\title{
El uso del marketing en el turismo: desarrollo del mercado de arte- sanías de la comuna kichwa Mandari Panga, Orellana, Ecuador
}

\section{The use of marketing on tourism: handicrafts market development of kichwa community Mandari Panga, Orellana, Ecuador}

\author{
Verónica Lisbeth Jaramillo-Pajuña ${ }^{1}$, Jacquelyn Pacheco $^{1}$, Cecilia Jaramillo ${ }^{1}$, Xavier Lastra-Bravo ${ }^{1}$ \\ ${ }^{1}$ Universidad Central del Ecuador. Facultad de Ciencias Agrícolas. Carrera de Turismo Ecológico. \\ Jerónimo Leiton y Av. La Gasca s/n. Ciudadela Universitaria. Quito. 170521. Ecuador
}

\begin{abstract}
Resumen
El presente trabajo se realizó con el propósito de desarrollar el mercado de artesanías de la comuna kichwa Mandari Panga, localizada en la provincia de Orellana, República del Ecuador, para orientar la actividad artesanal que los pobladores de la comuna vienen realizando durante varios años. Para ello, se caracterizó la oferta y la demanda a través de un estudio de mercado (encuestas, entrevistas y reuniones de trabajo), se determinaron los precios de las artesanías y se definió la forma de distribución y la promoción de las mismas. Se consideraron las variables clásicas del marketing mix (producto, precio, promoción y distribución) para canalizar los deseos de la demanda, y responder de manera adecuada a las necesidades del mercado actual. Como resultados se obtuvo la propuesta que da énfasis a responder a la demanda, innovar el producto y darle valor agregado; establecer precios que satisfagan las necesidades de ambos lados (productor y comprador); distribuir las artesanías de manera mixta; y, promocionar las artesanías haciendo uso de su marca y logo.
\end{abstract}

Palabras clave: estudio de mercado, producto, precio, promoción, distribución.

\begin{abstract}
The aim of this research was developing the handicrafts market of kichwa community Mandari Panga, located at Orellana Province, Ecuador, for guiding the handicraft activity carried out by the community residents for several years. The supply and demand was characterized by a market research (surveys, interviews and workshops), handicrafts prices were determined and promotion and distribution were defined. Classic marketing mix variables (product, price, promotion and place) were considered for channeling the demand choices and responding appropriately the current market's needs. As result, the proposal emphasizes on response to demand, product innovation and adding value. In addition, prices were established for satisfying the needs of craftsmen and buyers, mixed distribution strategy was set, and handicraft promotion by brand and logo was selected.
\end{abstract}

Keywords: market research, product, Price, promotion, place. 


\section{Introducción}

El Ecuador es uno de los 12 países megadiversos del mundo, así como también es rico en pluriculturalidad, con una riqueza étnica compuesta por 21 pueblos con costumbres y tradiciones propias (Proyecto Bosques, 2009). Gran parte de esta riqueza la encontramos en la región Amazónica. Esta región, con sus $114.448 \mathrm{~km}^{2}$, posee importantes áreas protegidas como el Parque Nacional Yasuní (PNY) y la Reserva de Biosfera Yasuní (RBY), la Reserva de Producción Faunística Cuyabeno, la Reserva Biológica Limoncocha, el Parque Nacional Sumaco Napo Galeras, entre otras.

Lastimosamente, esta riqueza biológica y cultural ha estado amenazada por el manejo irracional de los recursos naturales y la pérdida de valores culturales, producto de intereses inmediatistas, regionales y de grandes poderes políticos, que únicamente ven a la Amazonía como un potencial para la implementación de industrias petroleras, extracción de madera, intensificación de extensiones de cultivo de palma africana y, en décadas pasadas, la sobreexplotación del caucho, dejando de lado los valores ambientales y culturales que son la esencia de la región Amazónica.

En la actualidad, el Gobierno del Ecuador ha considerado al turismo como una prioridad nacional y como un eje importante para la reactivación económica del país. En una economía altamente dependiente de los ingresos del petróleo, el turismo es considerado como una actividad generadora de empleo y de redistribución de la riqueza, integradora y complementaria con múltiples actividades. Por ello, el turismo se constituye en una estrategia relevante para la superación de la pobreza y el desarrollo sostenible del país (MINTUR, 2009).

Un pilar fundamental en el turismo lo constituyen las artesanías, debido a que gran parte de los turistas o visitantes compran estos productos como un recuerdo que refleje las experiencias de sus viajes. Jiménez (2013) indica que el más importante atractivo para el rescate de la cultura y la promoción turística son las artesanías. Según PROECUADOR (2012), las artesanías son parte de la cultura y la historia del país. Aparico y Bodmer (2009) consideran que el creciente negocio turístico beneficia a las comunidades amazónicas, gracias al comercio de artesanías y a la presencia turística de danzas tradicionales.

La Organización de las Naciones Unidas para la Educación, la Ciencia y la Cultura (UNESCO, 2001), reconoce que el sector artesanal desempeña un papel determinante en el desarrollo económico local y en la lucha contra la pobreza, básicamente porque las producciones artesanales las realizan poblaciones con características similares, aun en los países llamados del primer mundo, algunas todavía nativas; por ende, la actividad artesanal se desarrolla en los cinco continentes.

Según Escobar y Montoya (2009), por tradición cultural, Ecuador es un país donde se elabora una gran variedad de artesanías con materiales muy diversos. La artesanía ecuatoriana se destaca por sus coloridos diseños y creativas formas, que reflejan la riqueza de nuestras cuatro regiones naturales. Paisajes, personas, animales, creencias y mitos son plasmados con gran habilidad por los artistas y artesanos; obteniendo artesanías que llevan a todo el mundo un mensaje de alegría y hermandad.

La artesanía kichwa merece una especial atención, no solo por su belleza y originalidad, sino también por su contenido y significado cultural. Por esta razón, la aplicación del marketing mix es fundamental para mejorar la actividad económica. De acuerdo con el Consejo de Desarrollo de las Nacionalidades y Pueblos del Ecuador (CODENPE), la economía de las familias kichwa es diversa, desde la caza, la pesca, la recolección, y el intercambio de productos y artesanías, las cuales siempre están reguladas por relaciones de reciprocidad y redistribución dentro de las matrices culturales que regulan las relaciones con los hombres y la naturaleza.

El marketing es un proceso social y administrativo mediante el cual individuos y grupos obtienen lo que necesitan, y desean, a través de la creación y el intercambio de productos y de valor con otros grupos e individuos (Kotler, 2008). 
Lafonth (2009) menciona que el marketing está compuesto por cuatro variables o elementos (Product $=$ Producto, Place $=$ Distribución - Pla$\mathrm{za}$, Promotion $=$ Promoción, Price $=$ Precio) que le permiten a la empresa direccionar su actividad económica, partiendo de las necesidades de los consumidores. Las 4 Ps del marketing también se denominan marketing mix, mezcla de marketing, mezcla de mercadotecnia o mix comercial.

Orjuela \& Sandoval (2002) mencionan que uno de los aspectos más importantes en la elaboración de proyectos es el análisis del mercado en el que se va a ofrecer el producto, ya que un conocimiento adecuado del mismo permite evaluar las posibilidades de éxito del bien o servicio evaluado.

El objetivo de este trabajo fue ayudar al desarrollo del mercado de artesanías de la comuna kichwa Mandari Panga, a través de la aplicación del marketing mix.

\section{Materiales y métodos}

\section{1. Área de estudio}

La comuna kichwa Mandari Panga se localiza en la región amazónica del Ecuador, en la provincia de Orellana, cantón Francisco de Orellana, parroquia Dayuma. Mandari Panga está ubicada en la margen izquierda del río Tiputini, en las coordenadas UTM 313632 Este y 9928910 Norte.

El clima es tropical y húmedo con una temperatura promedio anual de $26^{\circ} \mathrm{C}$. La pluviosidad oscila entre 1.800 a $4.500 \mathrm{~mm}$ anuales, los meses de mayor precipitación son mayo y junio. Está cubierta en un $80 \%$ de selva virgen con una altitud de 230 metros sobre el nivel del mar. Posee una gran biodiversidad, que constituye su principal atractivo (FEPP y MAE, 2003). Pero, también representa una amenaza, debido a que algunos de los pobladores se dedican a la caza y pesca ilegal, y a la tala indiscriminada del bosque.

$\mathrm{Su}$ principal fuente de ingreso es la agricultura, a través de la producción de yuca, chonta, hojas del bijao y verde, que son comercializados en la ciudad del Coca. Dentro de la actividad tu- rística, la comuna Mandari Panga recibe eventualmente a los visitantes, especialmente en el mes de diciembre, cuando tienen lugar sus festividades. En la actualidad, existe un proyecto turístico para la comuna Mandari Panga que se enfoca en alternativas de desarrollo sostenible, con eje en emprendimientos turísticos.

Existen dos sitios donde actualmente se comercializan los productos artesanales de la comunidad, el Malecón de la ciudad del Coca (MAC$\mathrm{CO})$ y el otro es el "Mercado Artesanal La Mariscal" en Quito.

\subsection{Metodología}

Para la investigación de campo se realizaron seis visitas a la comuna Mandari Panga, con el fin de sociabilizar y recopilar información de fuentes primarias. Se elaboraron fichas de inventario de atractivos culturales de los productos artesanales de la comuna para el estudio de mercado. Para caracterizar la oferta y la demanda se aplicaron encuestas a ocho artesanos de la comuna, pertenecientes al grupo activo de artesanos Mandari Sisa.

Se realizaron encuestas con preguntas cerradas a turistas nacionales (157) y extranjeros (163), en Quito (Mercado Artesanal La Mariscal) y en el Coca (Puerto del Coca, riberas río Napo). La población de estudio estuvo constituida por la demanda turística registrada por el Ministerio de Turismo en la provincia de Orellana en el 2010, 2.500 turistas nacionales y 6.100 extranjeros. La muestra se calculó mediante la fórmula de población finita con 1,81 de nivel de confianza y $6 \%$ de margen de error. También, se encuestó a comerciantes del Mercado Artesanal La Mariscal de Quito que se dedican a la comercialización y distribución de artesanías de todas partes del país (40 locales), y a los artesanos de la comuna, especialmente a los miembros activos de la asociación Mandari Sisa. Estas encuestas se aplicaron durante 3 meses claves octubre, noviembre y diciembre, que son los de mayor afluencia de turistas nacionales y especialmente extranjeros, debido a que en sus países de origen es temporada de vacaciones. Finalmente, se realizó un ensayo de comercialización de las artesanías en el Mercado Artesanal La Mariscal. 




Figura 1. Localización de la Comuna Mandari Panga. Fuente: Plan de Manejo Mandari Panga (2009).

\section{Resultados y discusión}

\subsection{Comunidad Mandari Panga}

La comuna Mandari Panga obtuvo la personería jurídica y la legalización del territorio a través del Acuerdo Ministerial $N^{\circ} 017$ del 8 de enero de 1998; y posteriormente con 25 socios (12 hombres y 13 mujeres) obtuvieron la escritura pública el 24 de febrero del 2000. En el 2012, los dirigentes de la comuna gestionaron sus Presupuestos Participativos en el Gobierno Autónomo Descentralizado Provincial de Orellana (GADPO). En el 2013, la solicitud fue aprobada y viabilizada a través de la Coordinación de Turismo de este GAD. Para ejecutar el gasto elaboraron el Perfil titulado "Implementación del Turismo Comunitario en la Comuna Kichwa Mandari Panga", que permitió dotar de una canoa de fibra de vidrio, una computadora y enseres de cocina; estos últimos posibilitaron el emprendimiento de gastronomía típica.

La comuna posee gran conocimiento ancestral en la elaboración de artesanías, por provenir de la mitología Canelo. Las principales artesanías que realizan son las relacionadas a la alfarería, bisutería y cestería.
La comuna Mandari Panga está iniciando la actividad turística con el apoyo del GADPO, lo que motiva a complementar el resto de acciones con la venta de artesanías, y también fomenta la conservación ambiental y el fortalecimiento cultural y económico de sus pobladores.

Un aspecto importante que promueve su actividad turística, y por ende artesanal, es la integración de los artesanos de la comuna al Museo Arqueológico Centro Cultural Orellana (MACCO).

Los problemas identificados de la comuna Mandari Panga son:

- Pocos pobladores de la comuna Mandari Panga se dedican a la elaboración de artesanías, lo que significa que la actividad tradicional está en peligro de desaparecer con las nuevas generaciones, que prefieren migrar a la ciudad más cercana (El Coca).

- Los artesanos desconocen técnicas innovadoras para la fabricación de sus productos.

- La venta de sus artesanías es limitada, debido a que no disponen de un sitio permanente donde puedan expender sus trabajos. 
- El proceso para elaborar las artesanías demanda de varias horas e incluso días, lo cual no justifica el precio al que se comercializan actualmente sus productos.

- Los artesanos tienen escaso conocimiento acerca del trato y atención al cliente, lo que dificulta la interacción con el comprador.

Para la solución de estos problemas, referentes a la actividad artesanal de los pobladores, se propuso:

- Invitar a más miembros de la comuna Mandari Panga para que se unan a la Asociación Mandari Sisa.

- Realizar talleres y capacitaciones en la elaboración de artesanías, utilizando nuevas técnicas y variaciones.

- Dotar a los artesanos de herramientas y materiales que faciliten la elaboración de artesanías.
- Buscar y abrir nuevos sitios de venta.

- Fijar precios basado en el costo de producción.

- Brindar charlas y capacitaciones referentes a la atención al cliente.

- Utilizar como eje principal la herramienta de la mercadotecnia, denominada "marketing mix", con la intención de darle un orden a todo el proceso y buscar la respuesta deseada en el mercado meta.

\subsection{Caracterización de la oferta y la demanda}

El $100 \%$ de los artesanos tienen de 36 años en adelante, y el 75\% son mujeres (Figura 2). Aparte de la actividad artesanal, los encuestados se dedican en su mayoría a ser amas de casa $(50 \%)$, seguido del $37 \%$ que se dedica a la agricultura, y el $13 \%$ es empleado público.

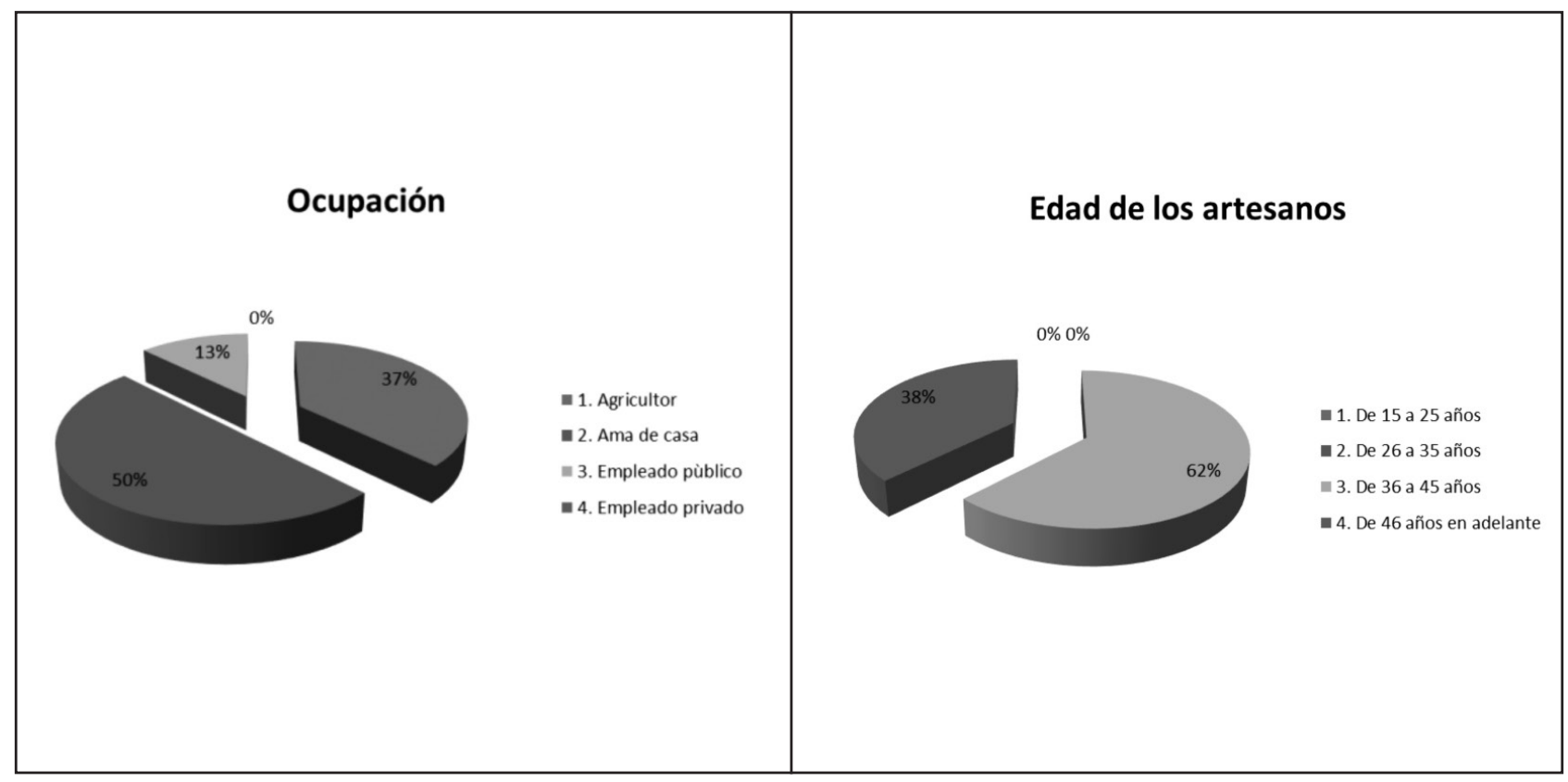

Figura 2. Características de los artesanos

El 50\% elabora tejidos (canastos, shigras, sombreros). Esto muestra que la mitad de ellos se dedica a hacer artesanías tejidas, el 38\% elabora bisutería (aretes, collares, pulseras) y tan solo el $12 \%$ conoce sobre la elaboración de recipientes de cerámica y barro (mukawas, kallanas) (Figura 3). El 50\% respondió que utiliza fibras naturales, un $37 \%$ semillas y un $13 \%$ barro. 


\section{¿Qué materiales utiliza para la elaboración de artesanías?}

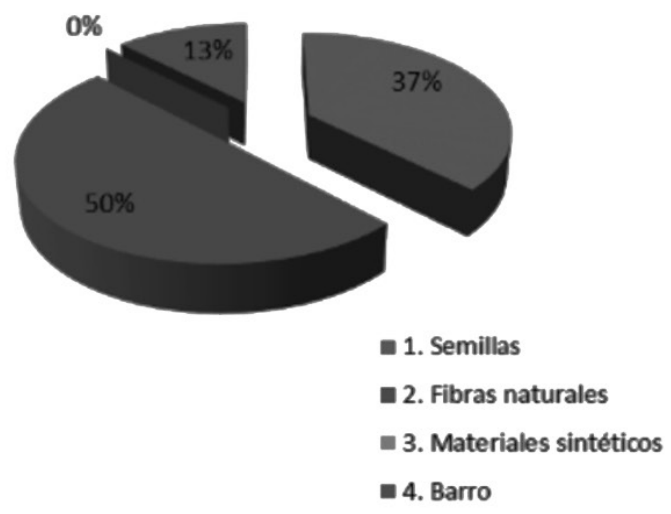

\section{¿Qué tipo de artesanía usted elabora?}

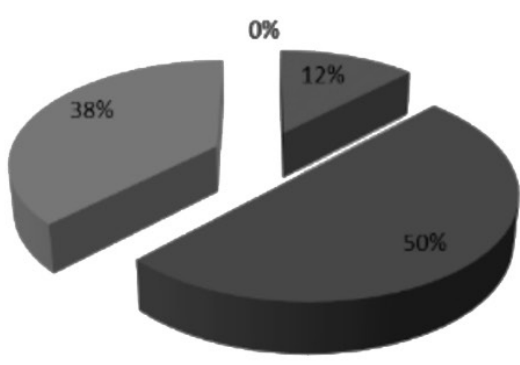

$$
\begin{aligned}
& \text { 1. Cerámica } \\
& \text { 2. Tejidos } \\
& \text { 3. Bisuteria } \\
& \text {-4. Otro }
\end{aligned}
$$

Figura 3. Características de la elaboración de artesanías

E1 75\% vende sus artesanías en la ciudad de El Coca y los demás en la comunidad. Quien más compra sus artesanías son turistas nacionales $(75 \%)$. También, mencionan que la venta a intermediarios nacionales es frecuente. Para los artesanos, el turista se fija más en la imagen de la artesanía (50\%). El $63 \%$ no satisfacen sus necesidades con la venta de sus artesanías, lo que indica que la actividad artesanal no está dejando ingresos económicos considerables para los artesanos. El 87\% respondió que el porcentaje de ganancia conveniente es de $31 \%$ a $50 \%$, y el $13 \%$ más de $50 \%$ de ganancia.

De los principales problemas que enfrentan los artesanos para el desarrollo del mercado de sus artesanías, el $50 \%$ respondió que no hay un sitio donde comercializarlas, un $25 \%$ cree que el problema es la falta de herramientas y materiales, un 13\% piensa que hay demasiada competencia y tan solo el $12 \%$ considera que les falta capacitación.

La edad de los comerciantes en su mayoría es de 36 a 45 años (35\%), seguido de un $28 \%$ que tienen entre 26 y 35 años, un $25 \%$ son mayores de 46 años y tan solo un $12 \%$ corresponde a comerciantes con edades de 15 a 25 años. La mayoría de los negociantes pertenece al género femenino (78\%). El $98 \%$ prefiere comprar bisutería, y el 2\% tejidos.

El $80 \%$ de turistas nacionales y extranjeros prefieren comprar bisutería, y el $20 \%$ opta por los tejidos. La mayoría de comerciantes $(85 \%)$ respondieron que están interesados en adquirir otro tipo de artesanía. E1 55\% mencionó que le gustaría comprar tejidos, así también un buen porcentaje se interesa por cerámicas, y las personas que mencionaron como interés a la bisutería, dijeron que les gustaría mayor variedad.

Los negociantes manifestaron que el $83 \%$ de compradores son turistas extranjeros y que tan sólo un $17 \%$ nacionales. Consideran que el turista se fija más en la calidad de las artesanías (42\%), que sugiere que un producto debe ser de calidad para tener una buena acogida en el mercado (Figura 4). Todos respondieron que los precios a los que venden las artesanías son adecuados, de igual forma los precios de venta al público ya están establecidos en el mercado. 




Figura 4. Características de la comercialización de artesanías.

El $80 \%$ respondió que el precio dispuesto a pagar por la bisutería sería de 1 a 5 dólares, y el $20 \%$ dijo que pagaría de 6 a 10 dólares. El precio que pagarían por los tejidos, en un $62 \%$, es de 1 a 5 dólares, mientras que un $38 \%$ pagaría de 6 a 10 dólares. El 67\% pagaría por artesanías de cerámica de 1 a 5 dólares, el $28 \%$ entre 6 a 10 dólares y el $5 \%$ de 11 a 20 dólares, todo depende de la complejidad, tamaño y detalles del trabajo (Figura 4).

Para el 47\%, el porcentaje de ganancia adecuado es de $25 \%$ a $30 \%$ (Figura 4 ). El $47 \%$ indicó que la presentación que prefiere el turista para las artesanías es que el producto venga en caja, y un $35 \%$ dentro de una funda de papel. El 90\% señaló que los fines de semana se vende más las artesanías, y tan solo el $10 \%$ dijo que los feriados. El 50\% aseguran que el mes más favorable es diciembre, seguido del mes de enero (27\%). Lo que muestra que diciembre, por estar en celebraciones como fiestas de Quito y Navidad, se da la mayor venta en el mercado artesanal "La Mariscal", seguido del mes de enero, en el cual se tiene una gran afluencia de turistas colombianos, porque en ese mes se encuentran en vacaciones.

\subsection{Perfil de los turistas nacionales y extranjeros}

La edad de los turistas, tanto nacionales como extranjeros, que predomina es de 26 a 35 años, con un $44 \%$ y $41 \%$ respectivamente, quienes gustan de viajar y conocer la naturaleza y cultura de nuestro país y tuvieron mayor disposición a ser encuestados (Figura 5). De acuerdo con el género, no se observaron diferencias significativas, ya que tanto hombres como mujeres visitan el Mercado Artesanal "La Mariscal" y el Parque Nacional Yasuní, atraídos por su atractivo natural y cultural. La mitad de turistas nacionales y extranjeros son solteros. 


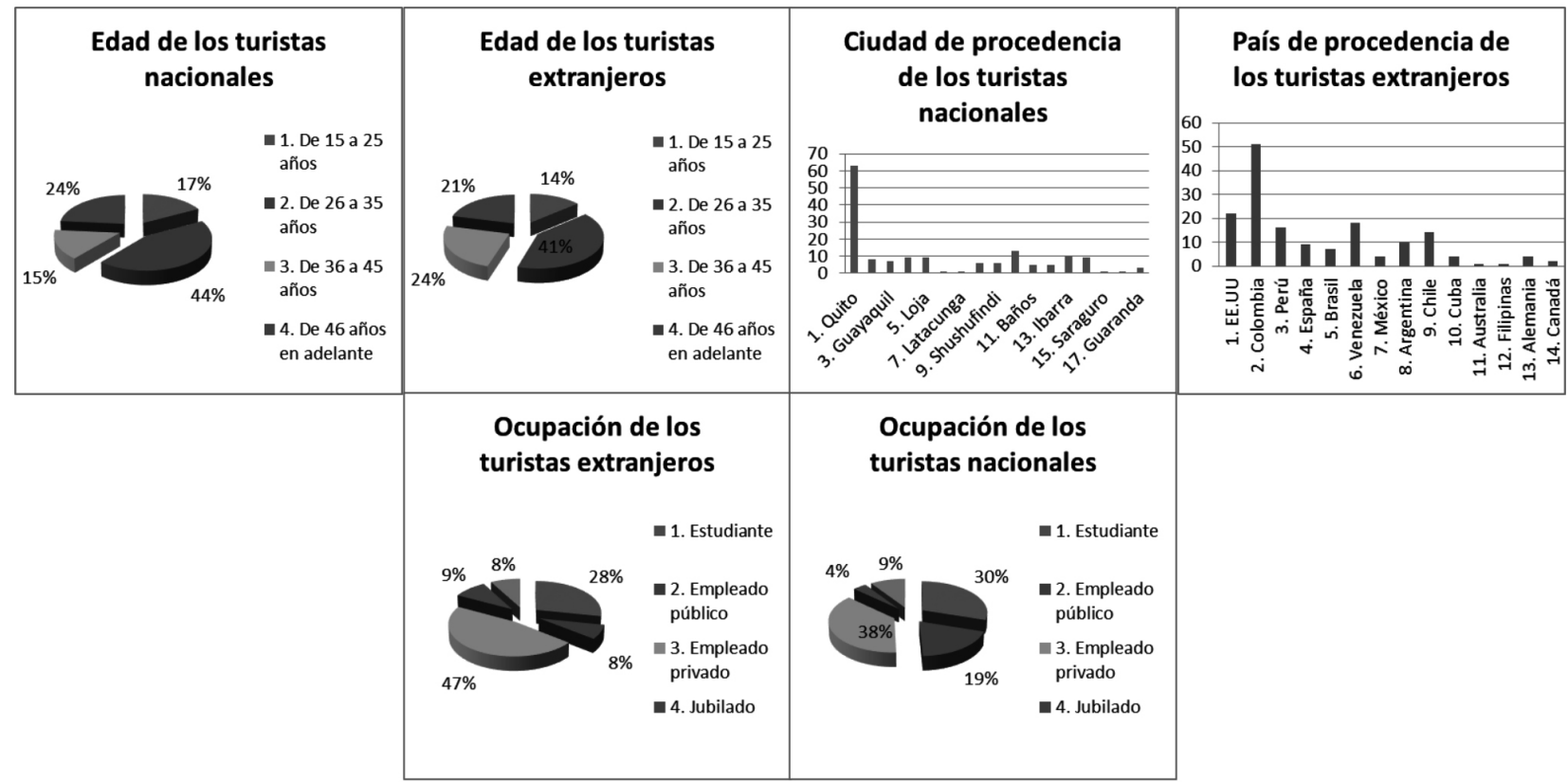

Figura 5. Perfil de turistas.

El $60 \%$ de turistas nacionales son de la ciudad de Quito (Figura 5). También, existe un número representativo de turistas de Lago Agrio. Hay un predominio de turistas colombianos que visitan Quito y El Coca aprovechando la proximidad con el Ecuador.

Tanto turistas nacionales como extranjeros, en un porcentaje significativo, son empleados privados (38 y $47 \%$, respectivamente), y tienen su propio negocio, seguido de un $28 \%$ a $30 \%$ que es estudiante, de pregrado o postgrado (Figura 5).

El 98\% de turistas nacionales, y el 93\% de extranjeros, mostraron gran acogida por los productos. El 74\% de turistas nacionales y el $64 \%$ turistas extranjeros han adquirido algún tipo de artesanía amazónica, y mencionaron que los materiales son muy atractivos y con valor cultural. Aquellos que no han adquirido artesanías amazónicas dijeron preferir los productos textiles; como la artesanía otavaleña o artículos elaborados en cuero. El 70\% de turistas nacionales y el 59\% de extranjeros prefieren la bisutería (aretes, pulseras, collares). El 89\% de turistas nacionales y el $92 \%$ de extranjeros dijeron que los precios a los que se comercializan las artesanías amazónicas le parecen adecuados. Lo que se traduciría en una gran aceptación de los precios actuales en el mercado.

El 63\% de turistas nacionales dijo que pagaría por la bisutería de 1 a 5 dólares. Mientras que, el
$60 \%$ de turistas extranjeros respondió que pagarían de 6 a 10 dólares. Estas respuestas muestran que el precio que los turistas nacionales cancelarían es bajo $\mathrm{y}$, en el caso de los turistas extranjeros pagarían un mayor valor, sin embargo, todo dependería de la calidad, complejidad y el tamaño del producto, como se desprende de los siguientes resultados.

El $93 \%$ de turistas nacionales y el $82 \%$ de turistas extranjeros pagarían entre 6 a 20 dólares por artesanías tejidas. Por tanto, el turista está dispuesto a cancelar un precio razonable por shigras, canastos y sombreros. El $62 \%$ de turistas nacionales y $63 \%$ de turistas extranjeros pagarían por artículos de cerámica de 6 a 10 dólares. Todos los valores obedecen a la complejidad, tamaño y detalles del producto. Los turistas nacionales y extranjeros compran las artesanías basándose fundamentalmente en la calidad (48\% y 54\%). Estos resultados sugieren elaborar productos con mejores acabados y atributos.

El 41\% de turistas nacionales se informaron sobre la Amazonía y sus artesanías a través de ferias y exposiciones. En relación al turista extranjero, el $39 \%$ manifestó haberse enterado a través de amigos, seguido de un $28 \%$ que se informó mediante ferias de exposiciones.

El 100\% de los turistas nacionales, y el $97 \%$ de los extranjeros, respondieron que la calificación al di- 
seño, color, variedad y materiales de las artesanías es excelente y buena. En general, la aceptación de las características de las artesanías kichwa, es sobresaliente.

\subsection{La comercialización}

La acogida de las artesanías denominadas bisutería, fue buena, es decir, los turistas compraron los productos a los precios actuales del mercado.

En referencia a los tejidos, los compradores prefirieron la shigra a los canastos, en lo concerniente al precio de las shigra, se vendió, pero a precios bajos $(\$ 10)$, es decir un precio $33,4 \%$ menos del precio sugerido (\$15). En relación a la cerámica, hubo turistas que preguntaron su precio, pero debido a la competencia de otros artículos de cerámica como réplicas de figuras precolombinas o cerámica andinas, no se concretó la venta.

\subsection{Segmentos de mercado}

Las artesanías kichwas son productos con gran aceptación en el mercado por parte de todos los grupos encuestados. Es así que, dentro de la demanda se encuentran comerciantes del Mercado Artesanal "La Mariscal", de sexo femenino que tienen edades entre 35 y 45 años, que prefieren comprar bisutería (aretes, collares, pulseras), inclinadas a comprar artesanías tejidas (shigras), interesadas en productos de calidad, quienes están conformes con los precios actuales, que pagarían de 1 hasta 10 dólares por los artículos y, que prefieren las cajas para comercializarlos.

En relación con los turistas nacionales; el mercado lo componen hombres de 26 a 35 años, solteros, procedentes de Quito y Lago Agrio, empleados públicos y privados, quienes anteriormente han adquirido este tipo de artesanías, prefieren la bisutería y los tejidos, pagarían de 1 a 5 dólares por la bisutería, de 6 a 20 por los tejidos de 6 a 10 dólares por la cerámica. Además, son turistas que se fijan en la calidad e imagen de los productos, optan por adquirirlos en un mercado artesanal $\mathrm{y}$, se informaron acerca de la existencia de la Amazonía y sus artesanías a través de ferias de exposición, amigos y familiares.

El segmento de mercado de turistas extranjeros lo componen mujeres de 26 a 45 años, solteras y casadas, procedentes de Colombia y Estados Unidos, empleadas privadas y estudiantes, que se inclinan por comprar bisutería. Los que anteriormente han adquirido este tipo de productos, prefieren la bisutería y tejidos, pagarían de 6 a 10 dólares por la bisutería, de 6 a 20 por los tejidos y de 6 a 10 por los artículos de cerámica, y se fijan en la calidad e imagen del producto. Al mismo tiempo, son personas que se interesarían en adquirir las artesanías en mercados artesanales, quienes se enteraron acerca de la Amazonía y sus artesanías mediante sus amigos, ferias de exposiciones e internet. Además, frecuentan sitios turísticos relacionados al entorno natural y gustan del patrimonio cultural ecuatoriano.

\subsection{Mix de Marketing}

\subsubsection{Ciclo de vida del producto (artesanía kichwa de Mandari Panga)}

Las artesanías de la comuna kichwa Mandari Panga se encuentran en la etapa de Introducción. En esta etapa, los artesanos producen versiones básicas del producto. Concentrándose en aquellos compradores que están mejor preparados para adquirirlas.

A medida que se avance por las siguientes etapas del ciclo de vida de las artesanías, se tendrán que formular continuamente nuevas estrategias de fijación de precios, promoción, y otras estrategias de marketing. La mejor posibilidad de conservar el liderazgo en el mercado consiste en dar los pasos correctos desde un principio.

Los artesanías de la comuna kichwa Mandari Panga, por ser un producto de consumo, se localizan en productos de compra, debido a que en el proceso de selección se compara adecuación, calidad, precio y estilo. Se determinó que dentro de la pirámide de las necesidades de Maslow, las artesanías se encuentran en la sección: estima y estética.

\subsubsection{Innovaciones al producto (artesanía kichwa)}

La marca Mandari Sisa Este responde a la denominación de la Comuna Mandari Panga y del grupo de artesanos Mandari Sisa, que en español significa "flor de la palma". El logo se estableció a través de una reunión con los artesanos. La imagen simplifica aspectos importantes para los artesanos (Figura 6), el sol que para ellos representa la principal fuente de vida y energía para la naturaleza, y la flor que representa a su comunidad. Además, los colores denotan tranquilidad, es así como el amarillo representa al sol, el café el color de la tierra, el verde representa al bosque y su flora. 


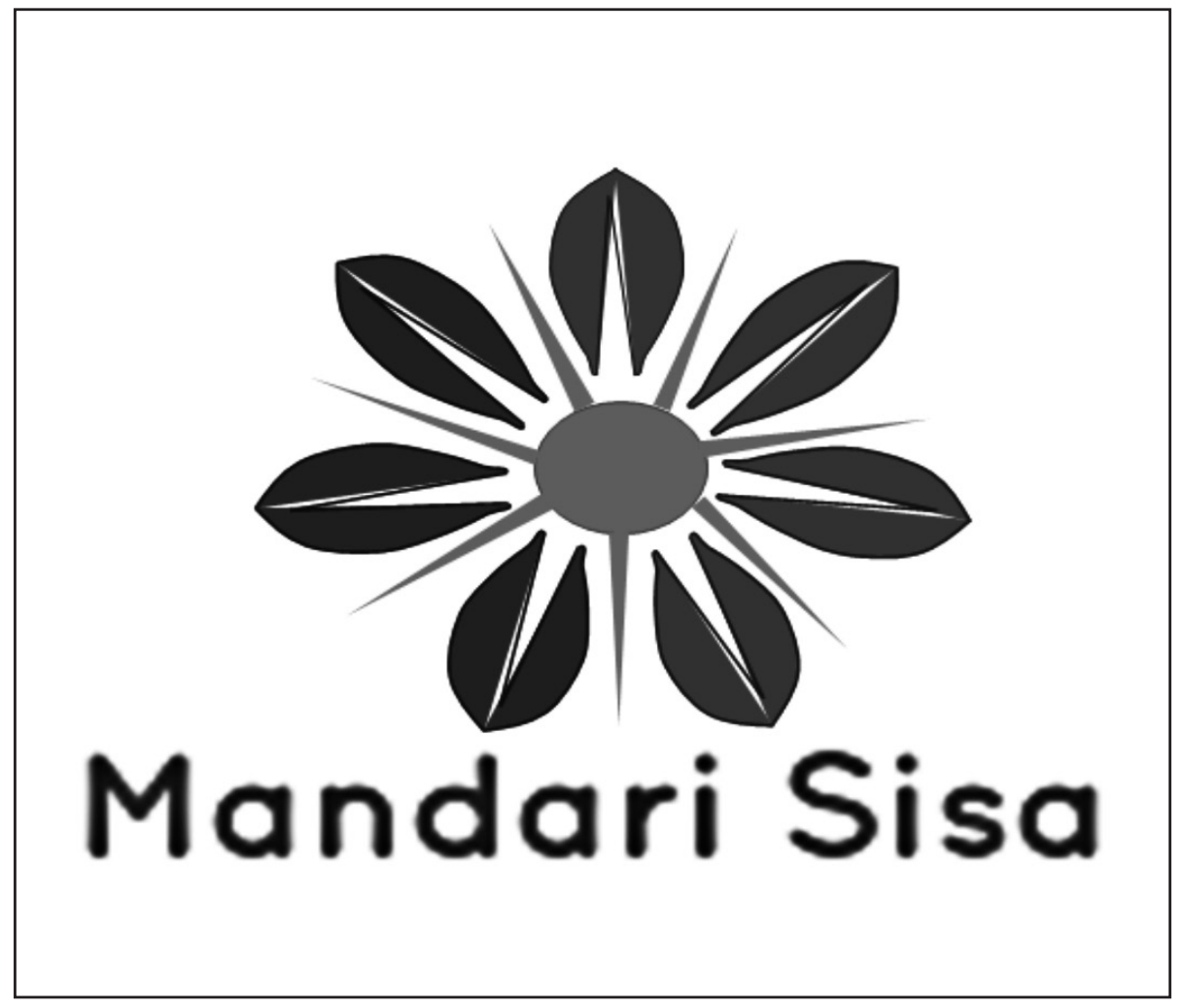

Figura 6. Logo de las artesanías Mandari Sisa

La marca Mandari Sisa se usará en todo producto artesanal que realice la comuna Mandari Panga, lo que incluye a la bisutería, cestería y alfarería o cerámica. El logo y la marca se utilizará en la impresión con pirograbador sobre las cajas de los productos, en la impresión de etiquetas, en tarjetas de presentación, camisetas y en gigantografías a usarse en exposiciones de las artesanías.

\subsubsection{Precio de las artesanías Mandari Sisa}

Para establecer el precio final de las artesanías Mandari Sisa, para su venta directa, se estimaron los costos de producción (materias primas, materiales y herramientas, horas de trabajo y gastos) y utilidad. Con lo que se superan las expectativas de ganancia del artesano y se establece un precio acorde al mercado actual y aceptable para la demanda. Los precios al por mayor, o para la venta a los comerciantes, corresponde al precio según las expectativas del artesano con una utilidad del 50\%. Además, los precios de las artesanías Mandari Sisa son similares a los de la competencia, Mercado Artesanal "La Mariscal" y el "Centro Cultural y Turístico Shuar AWAINKIR AKINMA" RENACER, siendo competitivos.
3.6.4 Distribución y promoción de las artesanías Mandari Sisa

El modo de distribución de las artesanías kichwas amazónicas se realizará de forma mixta, es decir, a través de canales directos e indirectos. Esto se debe a que turistas nacionales y extranjeros manifestaron que les gustaría comprar los productos dentro de un mercado artesanal o feria de exposición (con intermediarios), y también mencionaron que desearían comprar directamente en la comuna. La presencia del Museo Arqueológico Centro Cultural Orellana, en el malecón de El Coca, ayudará a la distribución de las artesanías Mandari Sisa.

Para la promoción de los productos artesanales kichwa se darán a conocer directamente a los comerciantes, ofertando los productos y mostrando sus cualidades. Así también, se dejarán muestras de productos para que los comerciantes experimenten la comercialización del producto. Se tendrá muy en cuenta la marca y exposición del producto, a través de tarjetas de presentación impresas en papel couché de 300 gr., etiquetas impresas en papel couché mate de 300 gr. y exhibidores. 


\section{Conclusiones}

La investigación de mercados realizada para los productos artesanales de la comuna kichwa Mandari Panga arrojó resultados importantes para el desarrollo de la comercialización de sus artesanías. Los datos más relevantes se refieren a la gran aceptación que tienen las artesanías amazónicas por parte de turistas nacionales con un $99 \%$ y extranjeros con un $93 \%$, siendo el segmento determinado de preferencia del producto: hombres y mujeres solteros en el rango de edad de 26 a 35 años, empleados en su mayoría en el sector privado, de procedencia principalmente de Quito, en el caso de turistas nacionales, y de Colombia de turistas internacionales, la preferencia por este tipo de productos se basa en sus diseños, color, forma, materiales y calidad, así como por ser elaborados con materiales naturales y poseer gran contenido cultural, los precios que estaría dispuestos a pagar son: de 6 a 20 dólares por artesanías tejidas, de 6 a 10 dólares por artículos de cerámica y por la bisutería de 1 a 5 dólares (nacionales) y de 6 a 10 dólares (extranjeros). Estos precios tienen la aceptación de turistas y comerciantes, y fueron fijados con los productores en base a sus costos de producción y en función del valor agregado por la marca y el empaque.

\section{Referencias}

Aparicio, P. \& Bodmer, R. (2009) Pueblos indígenas de la Amazonía peruana. Iquitos-Perú: Centro de Estudios Teológicos de la Amazonía (CETA).

Escobar, F. \& Montoya, G. (2009) Creación de una plaza de artesanías en el cantón Milagro. Proyecto previo a la obtención del Título de Ingeniero Comercial, mención: Recursos Humanos y Finanzas. Universidad Estatal de Milagro. Unidad Académica Ciencias Administrativas y Comerciales. Ecuador.

Fondo Ecuatoriano Populorum Progresio (FEPP) \& Universidad Técnica del Norte (UTN). (2004). Estudio etnobotánico de la comuna kichwa de Mandari Panga. Orellana, EC.

Jiménez, E. (2013). Estrategia de rescate de la cultura a través de las artesanías en la comunidad Simón Bolívar parroquia de Fátima - pro-
La oferta la constituyen los productos artesanales kichwa amazónicos como: la bisutería (aretes, pulseras, collares), la cestería (shigras, canastos, sombreros, abanicos) y la alfarería o cerámica (mukawas, kallanas, figuras de la naturaleza). Las artesanías como los abanicos, las bateas de cacao silvestre y los sombreros tienen ventajas competitivas por ser producidos únicamente por la comuna Mandari Panga.

Según el estudio realizado, el turista prefiere adquirir los productos dentro de un mercado artesanal o feria de exposición. También mencionaron que desearían comprar directamente en la comuna, por lo que sería importante aprovechar la presencia del Museo Arqueológico Centro Cultural Orellana, en el malecón de El Coca, para mejorar la comercialización de las artesanías, por lo que se decidió utilizar distribución mixta.

Toda la promoción se realizará utilizando la marca, tanto en productos como en exhibidores, además se informará sobre las características del producto y se resaltará la importancia social y ambiental.

vincia de Pastaza. Tesis de grado previo a la obtención del título de Licenciada en Turismo Ecológico. Universidad Central del Ecuador, Facultad de Ciencias Agrícolas Escuela de Turismo Ecológico, Quito-Ecuador.

Kotler, P. (2008). Fundamentos de marketing. Octava Edición, México. Prentice Hall Hispanoamericana S.A. pp. 5, 7, 30.

Lafonth, T. (2009). Las 4 p del marketing. Universidad de Córdoba, Colombia. 2009.

Ministerio de Turismo del Ecuador (MINTUR). (2009). Plan Integral de Marketing Turístico del Ecuador (PIMTE 2010-2014). Ecuador: Ministerio de Turismo del Ecuador.

Orjuela, S. \& Sandoval, P. (2002) Guía del estudio de mercado para la evaluación de proyectos, 
Seminario de prueba para optar al título de Ingeniero Comercial. Universidad de Chile, Facultad de Ciencias Económicas y Administrativas, Carrera de Ingeniería Comercial. Santiago-Chile.

PROECUADOR. (2012). Análisis del sector artesanías 2012. Dirección de Inteligencia Comercial e Inversiones Promoción de Exportaciones Especialista Sectorial de Artesanías. Quito-Ecuador.
Proyecto Bosques. (2009). Plan de manejo de la comunidad kichwa Mandari Panga. Ecuador-Orellana.

UNESCO. (2001). Artesanías creadoras. París: Unesco. Sección de Artesanías y Diseño. 